\title{
Wooden Bay Window (Rowshan) Conservation in Saudi-Hejazi Heritage Buildings
}

\author{
Adnan Abbas Adas \\ aaadas@kau.edu.sa \\ Department of Architecture, CED, king Abdulaziz University \\ P.O.Box 80210, Jeddah, 21589, Saudi Arabia
}

KEY WORDS: Rowshan, Rawasheen, Repair, Technique, Heritage buildings, Old Jeddah

\begin{abstract}
:
A prominent feature of the architectural style of heritage buildings in western Saudi Arabia (Hijaz) cities such as Jeddah is the extensive use in their facades of projected intricately carved wooden bay window (Rowshan sl, Rawasheen pl). Throughout Balad or the old town in Jeddah, the element of Rowshan can be found made from many different types of woods such as teak, Javan, mahogany, other types of african and middle eastern woods and with different sizes, proportions, and varied intricate ornamentations and motifs. Besides its aesthetic value, the rawasheen and their many components and parts provide other functions such as ventilation, lighting, and spatial and visual privacy for building interiors from the outside.

The profound degradation of Rawasheen is impacting the authenticity and heritage value of old buildings in historical Jeddah because of many factors that include: extensive moisture damage, using improper repair methods and joinery techniques to maintain rawasheen, using unsuitable cleaning products and wood paints, and replacing damaged parts with unkown types of wood. In order to prevent any further deterioration of Rawasheen, documentation of rawasheen and its components using recent digital methodologies and the utilization of proper repair techniques must be followed when working with these elements to ensure longevity of conservation, and preservation of value and authenticity.Through the disucssion of Rowshan repair methodology that was developed that include the digital documentation of all intricate details of rowshan panels and wood engraving which allowed replicating damaged elements beyond repair and applied to a listed building in old Jeddah, the paper provides Rowshan repair guidelines which relate to documentation, diagnostic methods, investigations and tests, repair methodology and reinforcement
\end{abstract}




\subsection{Introduction}

Saudi Arabia has fascinating architectural heritage such as can be found inits coastal cities and towns along the shores of the Red Sea. In Jeddah the gateway to the holy cities of Makkah and Madina the main cities of Hejaz,traditional buildings walls were built with red sea coral Mangbi stone with lime rendering and plaster and their facades are adorned with beautifully carved

wooden bay window Rowshan. However Neglected and abandoned for long periods in the past, those buildings became subject to decay and collapse.

Recently, interest in preserving Hejazi traditional buildings have soared due to increased awareness of Saudi authorities and general public who are initiating renovation and revitalization programs for old Jeddah's heritage building as a unique example of red sea basin traditional architecture

\subsection{Historical Jeddah}

Historical Jeddah is an outstanding example of arab moslem towns in Saudi Arabia dating back many centuries ago as a prosperous merchant and trading town. A rich traditional urban fabric with sedimentary coral stone buildings reveal outstanding architecture, with towering massing and protruding wooden balconies and verandas. These allow a glimpse into the richness of Saudi- hejazi buit up heritage, which is being recognized as a potential site for future world heritage status. Despite its conditions the old buildings of old Jeddah is still considered by many visitors as one of the intense visitor's experiences of Arab architecture Some of the architectural features in the old town of Jeddah is simply unique and cannot be found anywhere else. By recognizing the heritage value, the Kingdom of Saudi Arabia is taking an important step forward to preserve old Jeddah for future generations, by enhancing its value and authenticity.

\subsection{Rowasheen Investigation Methodology}

A number of Rawasheen in heritage buildings in old Jeddah were investigated including Sharbatly, Naseef, Basyooni and Abu Safiah buildings. Investigations of the wooden elements aimed at documentation of architectural details, detection of failure types, determination of deterioration factors, and elaboration of suitable conservation and renovation methods. Rawsheen in old Jeddah heritage buildings can be found extending from ground floor level to upper levels which typically reach four to five stories high . The Roshan can be recognized as a large projecting wooden structure on a building facade, with a recognizable latticed components. A typical Roshan is about $2.5 \mathrm{~m}$ in width, $0.5-0.70 \mathrm{~m}$ in projection depth, and $3.0-3.5 \mathrm{~m}$ in height. Rawsheen can be bigger in height and width, By combining the inside width of Roshan with its outside projection, its total width reaches 1.2 $\mathrm{m}$ that accomodate enough seating area . The roshan has an internal height of $2.7 \mathrm{~m}$. In general, when we observed the facades of traditional buildings in historical Jeddah, the large variation of Roshan types and the diversity of assembled parts can be clearly seen. Despite of the different variations, all types of Roshan are ultimately composed out of similar main parts, so the absence or presence of other secondary parts decides the Roshan's type. These parts can be observed in a single Roshan. A single complex Roshan can generally be divided into three separately made parts, from bottom to top, into Base, Body, and Head as shown in figure 1.

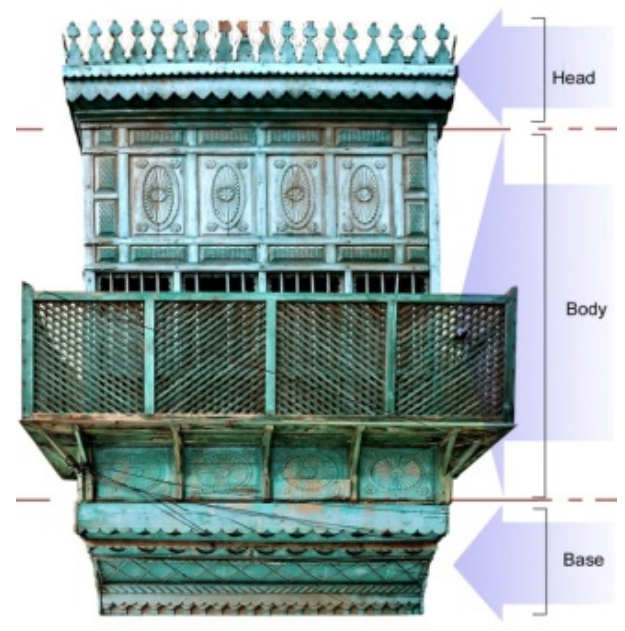

Fig .1 Roshan main parts adopted from Alitani (2011)

According to Etani et al (2011) Dense stero matching (DSM) as digital modeling technique offers unexpectedly good 3D results, from many perspectives because it has high geometrical precision with high level of visualization. This is why Dense stero matching (DSM) technique was used in documenting the roshan and its components as can be seen in and it yielded very good results

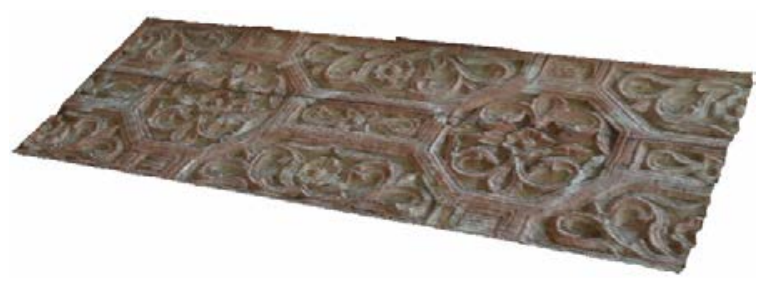

Fig.2 3D model of Roshan decorative panel

Generally, all wood failures in Rowshan were found to have been generated by many factors including mechanical, biological, chemcial, and physical factors. Detecting and recognizing these wood anomalies was done visually through the human eye by spotting cracks, holes and other abnormalities while using simple handheld microscopes, hand magnifier, etc. In addition detecting through feeling by hand of the tactile texture of wooden objects was used along with utilizing tools and instruments such as Moisture meter, Fractometer, microscopes, scanning electron microscope, polarizing microscope). Insects, birds and animals investigations, devices in a mycological laboratory, bending and contraction test meter.

\subsection{Rawasheen Decay Factors}

Environmental fluctuation is a major contributing factor in how wood deteriorates in Rawsheen. Wood undergoes physical stresses when there is fluctuation in relative humidity and temperature levels. The average realtive humidity in old Jeddah is relatively high most of the year and it is not suitable for wooden Rawasheen. 
High sunlight exposure is also considered to be an initiating cause of many deterioration processes in materials (also known as photo-oxidation). This can be observed in the yellowing, drying and cracking of wood when exposed to strong sunlight. Paint layer on wood will also fade in the presence of light. The presence of light alone is less of a detrimental factor compared to when it is combined moisture, which can generate chemical reactions leading to the breakdown of materials. Unfiltered natural sunlight is more harmful than other artificial light sources although they must still be monitored for their intensity and UV level. Hence, the control of light damage must be done in conjunction with other means of environmental control. Structural defects could be recognized because of wood moisture which increases by rain, condensed or capillary water, unsatisfactory ventilating, poor by designed or sloppy joints, etc. Decrease of mechanical properties (stiffness, strength) of wood as a consequence of changes in its structural levels - molecular, anatomical, morphological and geometric.

Mechnical factors include decrease of mechanical properties (stiffness, strength) of wood as a consequence of changes in its molecular, anatomical, morphological and geometric levels. Rheological distortion of wood by cyclical or durable mechanical and moisture stresses, defecting of wood elements as a result of cutting, large cracks and/or deformations as a result of increased load on the wooden structure or its individual elements by using an excessive load and stress (e.g. replacement by using different kind of wood).

In Sharbatly heritage building shown in Figure 3., main wood damage in Rawasheen was detected as a result of wooddestroying biotic agents and wood-destroying insects.In addition chemicals factors also affected the decay of wood in as result of exhausts from cars and trucks and smoke from industrial and commercial facilties in the form of dryness causing cracks and splitting of layers. Other factors include material faults (presence of bark, large knots in wood), water damage as result of capillary actions, unsatisfactory ventilation, poor design and sloppy joints, undersized wood elements, using wood with a moisture content of above $20 \%$, no or inadequate protection against wooddestroying fungi, moulds and insects.

The types, ranges and degrees of biodegradation of Rowshan have been significantly dependent on The location of the heritage building in the historical Jeddah and the location of the degraded element in the ancient wooden structure wooden elements situated near to roof gutters, wooden elements, under/near to the loose or damaged roofing material, wooden elements under opened skylights, Wooden elements near to ground or in contact with ground, etc.) and area of contact of wooden elements with external walls. It is also found that damage by insect is not rare and it can be found also in other wooden elements because the minimal moisture content of wood for activity of Callidium violaceum and A.punctatum is only $10 \%$. Furthermore the environmental factors which affect wooden elements include light, temperature, humidity, pollution, insect damage, micro-biological growth, use of inappropriate materials, and inappropriate handling of objects.

These damages have a cumulative and usually irreversible effect. Hence, it is crucial that preventive measures be adopted to reduce the risks of such damages. The use of light is an integral function in any historical building. Therefore, it is important that light sources, whether artificial or natural, must be made safe for the long-term preservation of wood.
This protection can take several forms such as lowering the light level; removing the more harmful UV radiation by means of filters; using a light diffuser for artificial light source which will reduce the intensity light falling on objects; and reducing the amount of time that wood is exposed to light.

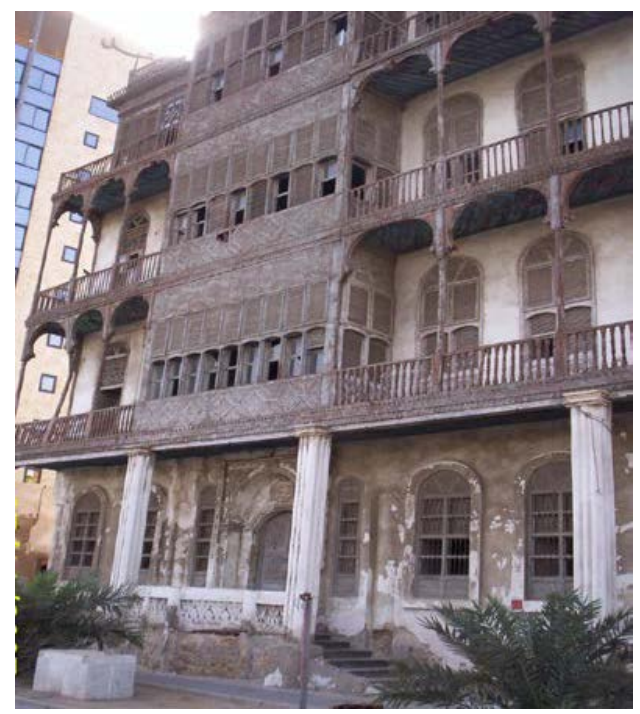

Fig 3. Rawsheen in Sharbatly building

It may seem inevitable that chemical and physical changes must befall wood material, but if we understand how objects deteriorate and anticipate the causes of such deterioration, then it is often possible to slow down these changes. The most important step in preventive conservation is to keep wood in heritage buildings in a dry state. That could be achieved through ensuring that roof drainage, guttering and storm water disposal systems are working properly. That there are no plumbing leaks, and that any surface water is drained well away from walls. Under floor spaces should be kept well ventilated. This will significantly reduce the risk of swelling, shrinkage, and cracking of wood, attacks by micro organisms (Fungal, Bacteria, Achiness, etc.) and attacks by insects (termites, borers, etc.)

In order to control termite in historical Jeddah heritage buildings we must incorporate termite shields (ant caps) on stumps and piers. These are not intended to prevent termites entering the timber above, but to slow them down and force them to build shelter tubes out and around the shields, where the tubes can easily be seen. The wood must not be wet and its moisture content must not be above $20 \%$. Damaged elements of Rowshan can be either be replaced with new ones using new parts of the same kind of wood and sized from the 3D digital models prepared during documentation as shown in Figure 4., or reinforced by stiffening of weakened parts of the wooden elements or indirect reinforcing

Lab testing was done to measure the effectiveness of the cleaning methods. Three methods were shown to be effective and should be followed. These are removing hard and solid dirt by mechanical cleaning (i.e. by using all kinds of soft brushes and vacuum tube. Scalpels, pins and spatulas could also be used), chemical cleaning by using organic solvents. Testing proved that Trichloro Ethylene was the best material used for dismantling the thick old paint layers a very gentile 


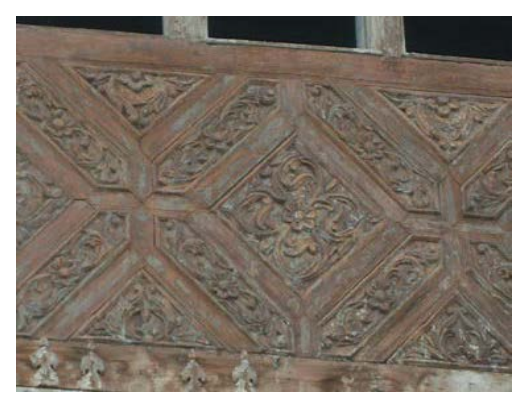

(a) Original decorative pattern of Roshan panel

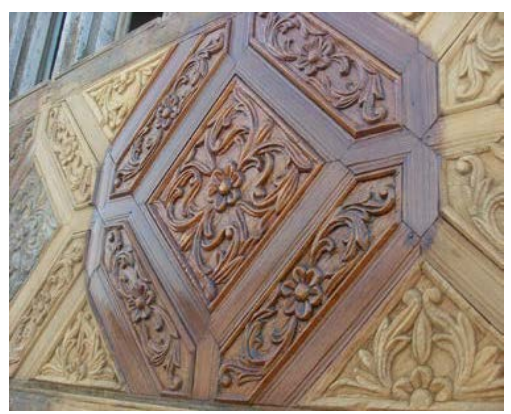

(a) New panel with similar decorative pattern

Fig 4. Repairing Rawsheen in Sharbatly building

and carful cleaning by using a Piece of cotton wet with a mixture of: 1 Ethyl Alcohol: 1 Thinner: 1Benzene is used to remove the traces of the paint. Other individual organic solvents or a mixture of some of them are applied to remove different kinds of dirt and spots such as acetone, benzene or thinner to remove wax, morphlene, berydene or die chloro ethylene to clean fatty and oily dirties. Solvents such as hydrogen peroxide and ethyl alcohol or chloramine to remove insects traces. Cleaning by using enzymes to remove dirt in wooden elements that could not be removed by traditional methods is done by changing them into simple substances

Consolidation of damaged wood in Rowshan could be achieved mainly by two methods. Either using an adhesive material (i.e. Polyesters, epoxy resin and other polymers) in combination with linking rods or consolidation of very deteriorated and fragile surfaces of wooden elements using most suitable material and process such as paraloid B 72, paraloid B 44, primal (AC-61), Estel 1000, Paraloid B 82, and Silo 111. Paraloid B72 dissolved in Tri chloroEthylene and also the emulsion of Primal (AC-61) was found to be the best materials to be used and they could be applied to the surface by brush pressuring. Extension method, using both natural wood and carpentry joints can also be used. Some conditions have to be taken into consideration during using this method such as the type and length of the joints, the deflection and bending strength of the steel linking rods (in case they are used), and the influence of the binding agents (mixture of resins with sawdust) on bending properties of the materials of wall buildings near by. Filling gaps, cracks and missing parts by using either solid wood or binding agents (mixture of natural agents and/or synthetic polymers with suitable fillers sawdust, glass micro balloon, etc. Wood was also fumigated with methyl bromide. Themol was also used for controlling micro organisms and such a procedure requires specialist's advice and skills.

\subsection{Recommendations}

All types of Rawsheen in old jeddah should be documented using 3D digital modeling of all its parts which should also be examined and inspected on regular basis. A complete inspection by an expert eye has to be done for all the wooden components and its elements to find out any sign of environemntal or moisture damage, micro organisms (rot, fungal growth) or insects attacks (termites, borers, spiders) damage. This kind of investigation must be carried out in the whole wooden elements of the building including the subfloor spaces, the flooring and framing, the roof spaces, the ceilings, the doors, the windows. Any sign of breakage or distortion or cracking in the Rowshan should also be investigated. External paint finishes for splitting should be checked because it may indicate water penetration to the wood beneath. A regular cleaning of the wooden Rowshan must be carried out to remove dust each week. This could be done by using a special kind of soft brushes and a vacuum cleaner. Specific steps can be taken to modify the environment that all wooden objects in facades in order to cushion the negative effects arising from the various deterioration factors. Adequate chemical protection should be directly used to protect wooden Rowshan against wood-destroying fungi, moulds and insects. All repair work should aim to restore the Roshan to its original shape, size, and design using the 3D digital models prepared during documentation

\section{References}

Alitany,Redondo, and Adas, 2011. A New methodology for A Detailed 3D Modeling and Documentation of the Complex Architectural heritage Elements: Case Study of Wooden Projected window "ROSHAN" in the Old City of Jeddah, Procedding of first Saudi Symposium on Urban Heritage, $\mathrm{p}$ $161-180$

Remondino, F., El-Hakim, S. F., Girardi, S., Rizzi, A., Benedetti, S. and Gonzo, L., 2009. 3D virtual reconstruction and visualization of complex architectures-the "3D-ARCH" project. International Archives of Photogrammetry, Remote Sensing and Spatial Information Sciences, 38(5/W1):9 pages (on CD-ROM).

Fassi, F.,2007. 3D modeling of complex architecture integrating different techniques - a critical overview.The Int. Arch. of the Photogrammetry, Remote Sensing and Spatial Information Sciences, Zurich, Vol. XXXVI-5/W47, 11p.

Angawi, S.M.,1995 "The Roshan a Main Feature of the Hedjaz Architecture" Colored Glass and Mushrabiyyah in the Muslim World. Cairo: Research Centre for IslamicHistory, Art and Culture, 1995.27-52.

Abdalla Y. Bokhari, 1983: Integrating Traditional Areas into the Modern Urban Fabric Conservation in the Historic District of Jeddah, the Aga Khan Program for Islamic Architecture, Saudi Arabia.

Andreas Hauser, 2008 . Saudi Arabia Historic Cities along the Red Sea Coast, Saudi Arabia Destination Report at Labels Destinations Inter-Culture, Tourism

David A. Webb, 1990. Wood Preservative Treatments for Crossties and Potential Future Treatments, Koppers Industries, Inc. The Railway Tie Association Annual Meeting Birmingham, Alabama, October 10-12, Feller, F.: Accelerated 
Aging photochemical and thermal aspects, The Getty conservation institute, US. 1994

Ladislav Reinprecht: Biodegradation and Treatment of Ancient Wood in Slovakia,Technical University in Zvolen, T.G.Masaryka 24, Zvolen, SK-960 53, Slovak Republik

Moncrieff, A \& weaver, G.: "Cleaning" the conservation unit of the museums \& Galleries commission; poutledge; 1994.

Paul Hennon: Deterioration of wood from live and dead Alaska yellow-cedar in contact with soil, Bessie Woodward, Patricia Lebow 2000

http//upload.Wikimedia.org/common/7/72/ruins_in_Al Balad jpg 